\title{
Slowing in Money Growth: The Key to Success in Curbing Inflation
}

\author{
by KEITH M. CARLSON
}

T HE ROLE of monetary actions in the administration's new economic progrm has received little emphasis. Controlling inflation is an important objective of the program, yet a course for monetary actions has not been proposed. Historical experience in the United States and other countries indicates that the rate of inflation is related very closely to the trend rate of monetary expansion.

Inflation has been a major economic problem since 1965, but experience since 1969 has been especially frustrating to the nation's economic policymakers. InAlation continued unabated in 1970, while unemployment rose sharply, and has since persisted in the face of relatively high unemployment. Conventional stabilization actions taken in the last three years to reduce the growth of money and Federal expenditures have had their major impact on output rather than on the price level. This development has led some analysts to become skeptical about the usefulness of traditional monetary and fiscal actions in coping with the current economic situation.

The new economic program was announced on August 15 , outlining a set of measures designed to deal with the problem of simultaneous inflation and relatively high unemployment. ${ }^{1}$ A temporary wageprice frceze was implemented, and a nember of fiscal actions were recommended with the objective of stimulating output and employment. The second phase of the program takes the form of Government intervention in private wage and price decisions for purposes of making certain that the rate of advance of constmer prices is reduced to below a 3 per cent amnual rate by late 1972 .

There are two major views prevailing with regard to the current problem of simultaneous occurrence of high unemployment and rapid inflation. One view stresses the role of "market power" as a factor influ-

The program also included important provisions relating to the international system of exchange and the U. S. balance of payments. These provisions are not discussed here. encing recent price level movements." The other view is a part of the monetarist explanation of economic processes, where the rate of inflation is determined by the trend of monetary expansion. This latter view attributes the simultaneous occurrence of inflation and high and/or rising unemployment to uncertainty regarding the state of total demand and the costs of information and adjustment involved in making price and output decisions. These two views relating to the current economic situation are discussed along with their policy implications. Preceding the discussion of these two views is a brief survey of economic developments from 1969 to the present.

\section{Economic Developments From Late 1969 to the Present}

Monetary and fiscal actions turned restrictive in late 1968 and carly 1969, and this policy stance was maintained until early 1971. The money stock rose at a 4 per cent average annual rate from early 1969 to late 1970, following an 8 per cent increase in the year ending first quarter 1969. So far this year monetary actions have been very stimulative, with the money stock rising at about a 9 per cent annual rate from January to September.

Fiscal actions became less expansionary after passage of the Revenue and Expenditure Control Act of 1968, but more recently have turned stimulative. Federal expenditures rose at a 6 per cent average annual rate from mid-1968 to late 1970 , compared with a 15 per cent average rate of advance in the previous three years. Since the fourth quarter of 1970 , growth of Federal expenditures has accelerated to more than a 10 per cent rate. The income tax surcharge was implemented in mid-1968, then allowed to expire in mid-1970.

These stabilization actions, while having limited success in slowing intlation, have had their primary impact in reducing output growth and increasing un-

2The term "market power" is ambiguous in its meaning. As used here it is meant to encompass several views, including "cost-push," "administered price," and "sellers" inflation. 


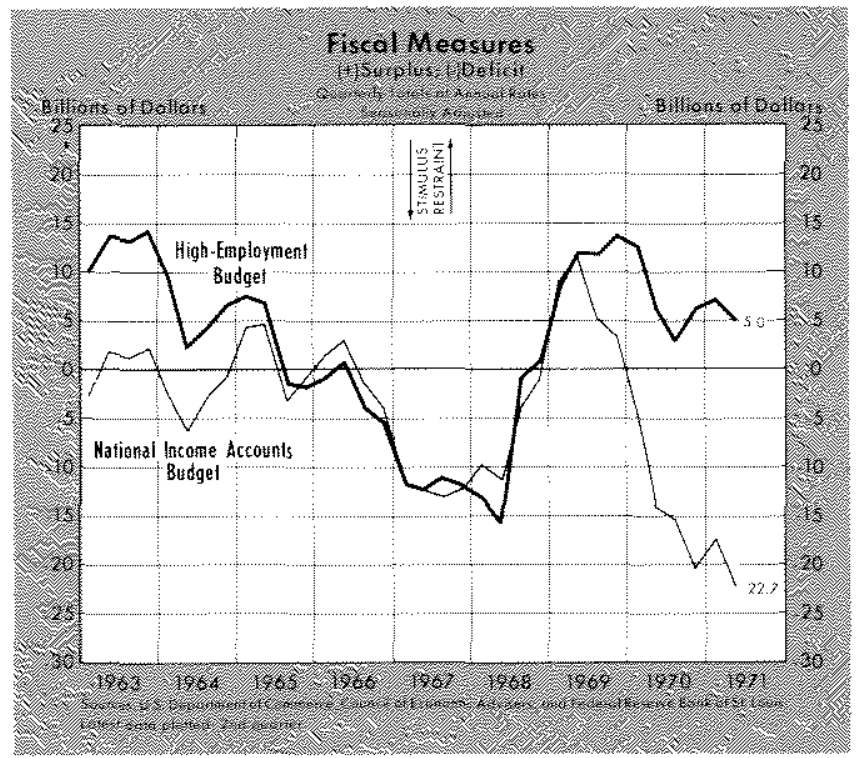

employment. The average level of prices advanced 5.7 per cent from fourth quarter 1969 to fourth quarter 1970, then slowed slightly to a 4.7 per cent annual rate. Unemployment increased from 3.6 per cent of the labor force in December 1969 to 6.2 per cent a year later, and has remained near this level, averaging 6 per cent in the first nine months of 1971.

A year before unemployment started rising, unit labor costs, which had been rising since 1965, accelerated further, reflecting a slowdown in productivity. Compensation per man-hour rose at a 7 per cent average rate from late 1968 to second quarter 1971, the same as from late 1965 to late 1968 . In contrast, output per man-hour slowed to a 1.2 per cent rate of increase after late 1968, well below the 2 per cent average rate of advance from late 1965 to late 1968. As a result,

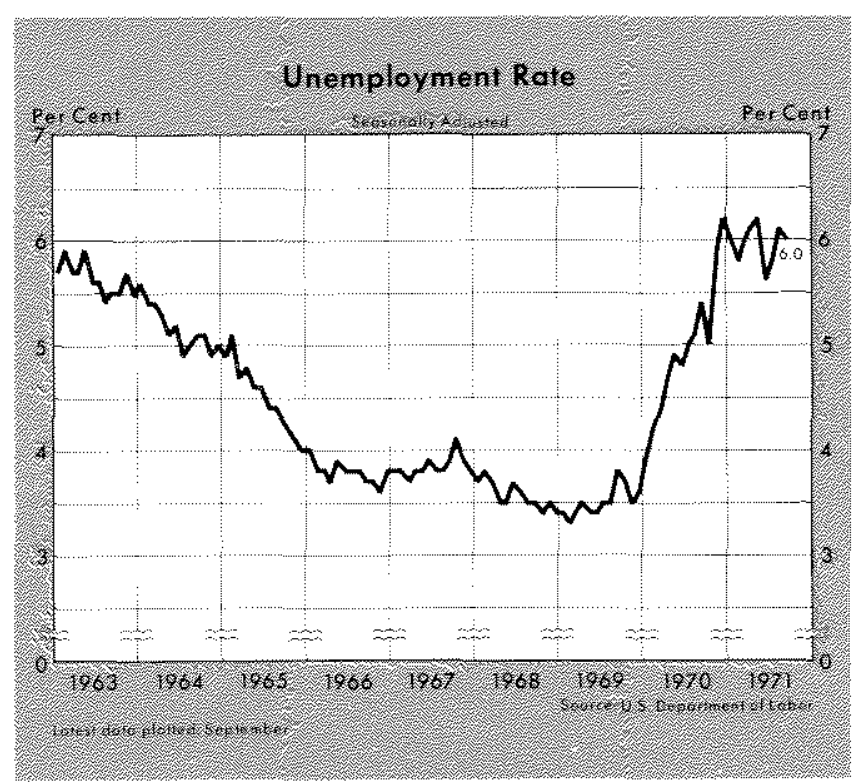

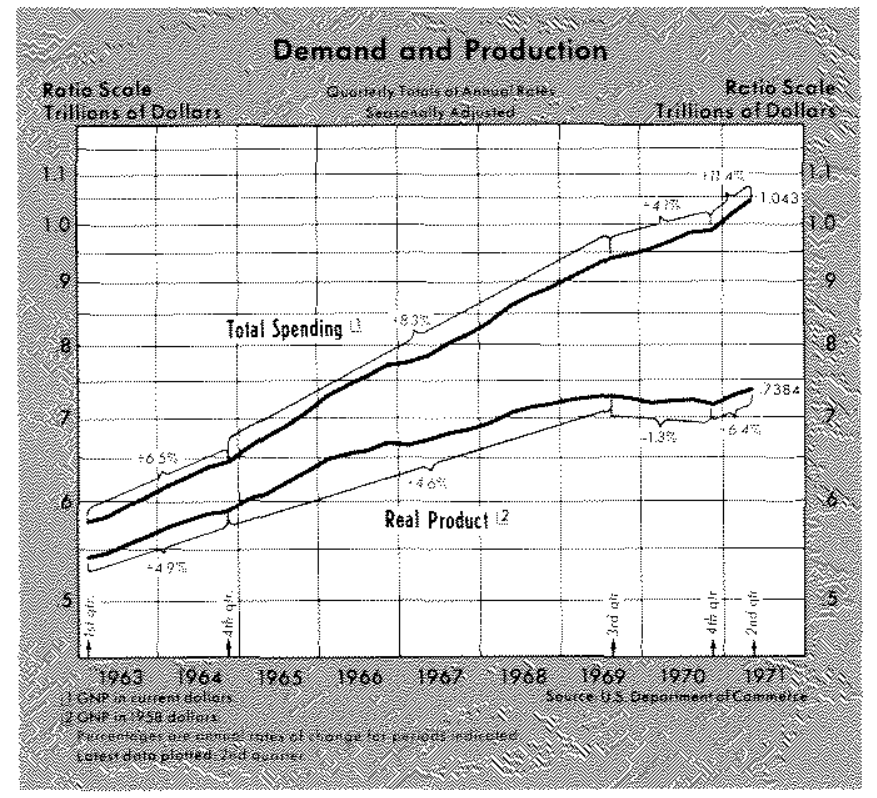

unit labor costs have increased at a 5.8 per cent average rate since late 1968 , compared to a 4.3 per cent rate from late 1965 to late 1968 .

\section{Simultaneous Occurrence of Inflation and Unemployment: Two Views}

Inflation is a common economic problem, but inflation in conjunction with high and/or rising unemployment is not so common. In the United States since

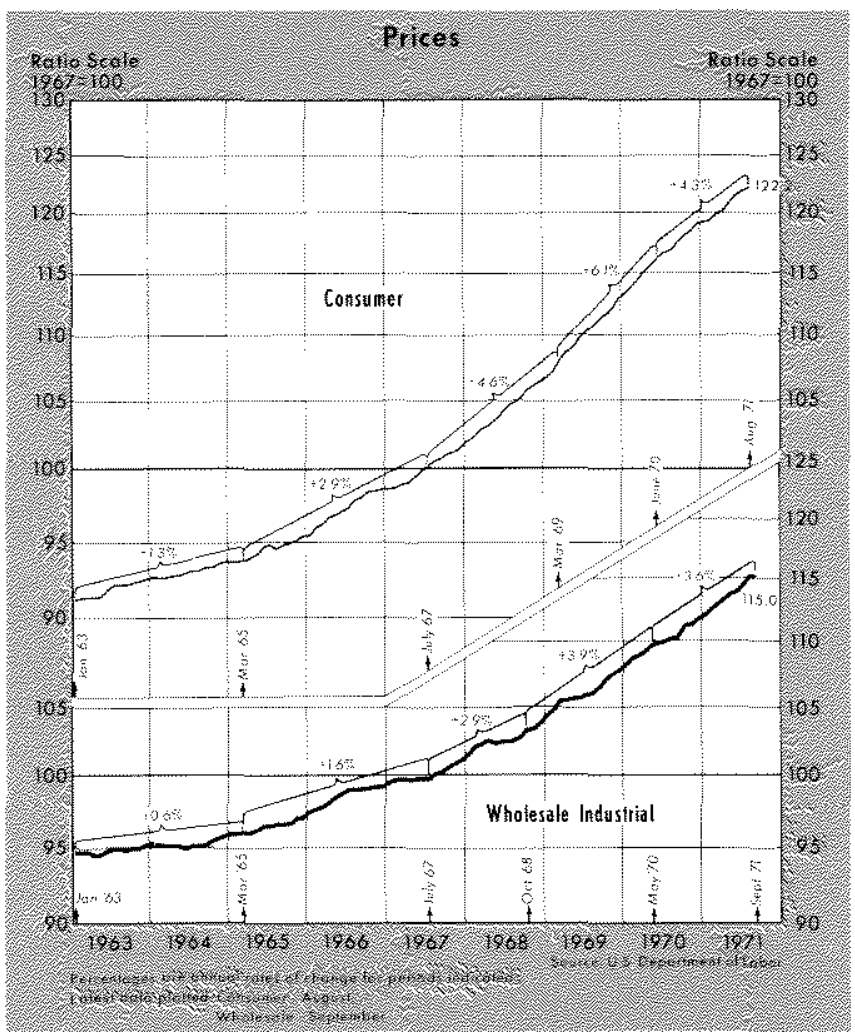


World War II, there have been few instances when rapid inlation and high unemployment have persisted together for a significant period of time. Any such experiences lead some observers to develop the opinion that conventional monetary and fiscal actions are not adequate for the task of achieving what seem to be conflicting social goals.

Explanations of the simultaneous occurrence of high unemployment and inflation can be divided into two categories. One attributes the source of the dilemma to an "excess of market power" among certain economic units, and advocates Government intervention in market pricing to supplement conventional monetary and fiscal policies. The other views the inflationunemployment dilemma as a result of rational economic behavior in the face of uncertainty, and stresses monetary and fiscal actions as the means of restoring high employment and relative price stability: ${ }^{*}$

\section{Market Power View}

According to the "market power" view, economic units, most commonly labor or businesses, are said to have excess market power when the prices of the goods or services they sell can be pushed up despite stable or falling demand. For example, because of substantial bargaining power, union wages may be pushed up faster than productivity advances. Firms respond to the increase in unit labor costs by increas ing their prices so as to protect their profit margins. According to this illustration, possession of market power by either labor or firms (or both) causes prices to increase in the face of stable or declining demand.

Little evidence has been offered to support the market power view as it applies to the conjuncture of inflation and unemployment. For inflation to occur (not just a once-and-for-all increase in the price level) when demand is stable, market power must be growing, or the use of existing market power must be increasing. The existence of market power, however defined, probably means only that the price level is higher than it would be if no such market power prevailed. If one is to argue consistently within this view, a continuing rise in the price level can persevere despite stable demand only if market power or its use continues to grow.

3Those who demonstrate impatience with conventional monetary and fiscal actions are not prepared to abandon such policies. Rather, these analysts feel that conventional stabilization actions need to be supplemented at certain times to improve their effectiveness. On the other hand those who oppose a supplement in the form of Government intervention do so because they feel that the effectiveness of traditional actions would be hindered by such intervention.

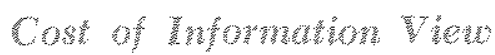

The cost of information view concerning the simultaneous occurrence of inflation and unemployment emphasizes the lags in adjustment of prices to an excess of total demand relative to total supply. $A$ slowing of growth in total demand following a long period of excess demand and inflation, according to this view, can produce continuing inflation along with declining output and rising unemployment. Such a situation occurs, and is to be expected, because information about changes in total demand is not available without cost to decision-making units.

Information about demand can be acquired only at a cost, and that cost varies with the speed at which it is obtained. Firms and households must incur a high cost per unit of information if they are to determine quickly that a change in total demand has taken place. There are also costs involved in adjusting prices and output, so prices can be expected to respond only slowly to a change in total demand. Under such circumstances of tucertainty, past price and demand changes frequently are used to form expectations about most likely future changes, and these expectations about demand will lag behind the actual facts of the demand situation. Thus, following a period of accelerating inflation, as from 1965 to 1969 , there is a tendency for infation to continue until changed economic facts are recognized and eventually lead to expectations of a slowing in inflation.

\section{Policy Implications of the Two Views}

Evidence that clearly supports one view as opposed to the other is difficult to develop. Nevertheless, the implications of the two views for monetary policy are of great significance and require further discussion.

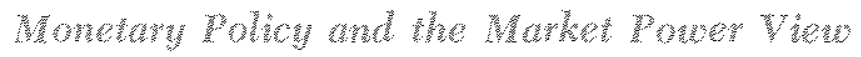

Since the problem of inflation in conjunction with unemployment is viewed by some observers as one of excessive market power, the natural policy implication is to curb the growth of such power or the exercise of existing power. A policy of Govermment intervention to guide prices and wages in line with productivity would supposedly lower the rate of inflation sooner than otherwise. Furthermore, the implication is that with prices and wages directly controlled in

4This view does not deny the existence of market power, but it does deny the growth or growing use of that power as a major factor explaining inflation.

Note that atterition is focused on the inflation aspect of the problem. There is no disagreement between the two views on improving the operation of free markets. 
this way, monetary and fiscal actions can properly be conducted towards stimulating total demand. An in crease in total demand with prices "directly" controlled would be reflected in increased output and employment.

\section{Montery policy and the cont of Infomation Vicu}

The information-cost view of the inflation-unemployment dilemma is that the current situation is "temporary." Following four years of accelcrating inflation, the length of this period of adjustment to slower growth in total demand is probably quite substantial. However, according to this view, it is desirable for the economic system to complete the adjustment without direct Government intervention in the price and wage policies of private economic units. Direct intervention in the form of wage-price-productivity formulae runs the risk of being viewed as a substitute for anti-inflationary monetary and fiseal actions; the return of monetary growth to a sustainable noninflationary rate consequently may be delayed. Wage-price standards, when accompanied by sustained rates of monetary expansion in excess of the growth rate of potential output, will not prevent the creation of pressures which eventually result in the abandomment of any system of guidelines. Furthermore, controls hamper the operation of free markets, which are required to allocate resources according to consumer wants.

\section{Conclusions}

Given that the new economic program is concerned ultimately with achieving high employment with relatively stable prices, historical experience indicates that monetary expansion should be maintained at a rate

6The experience with wage-price guideposts during the $1962-66$ pertod is a case in point. See the 1970 Annual Report of the Council of Economic Advisers (Washington, D.C.: U. S. Government Printing Office, February 1970) pp. $23-25$.

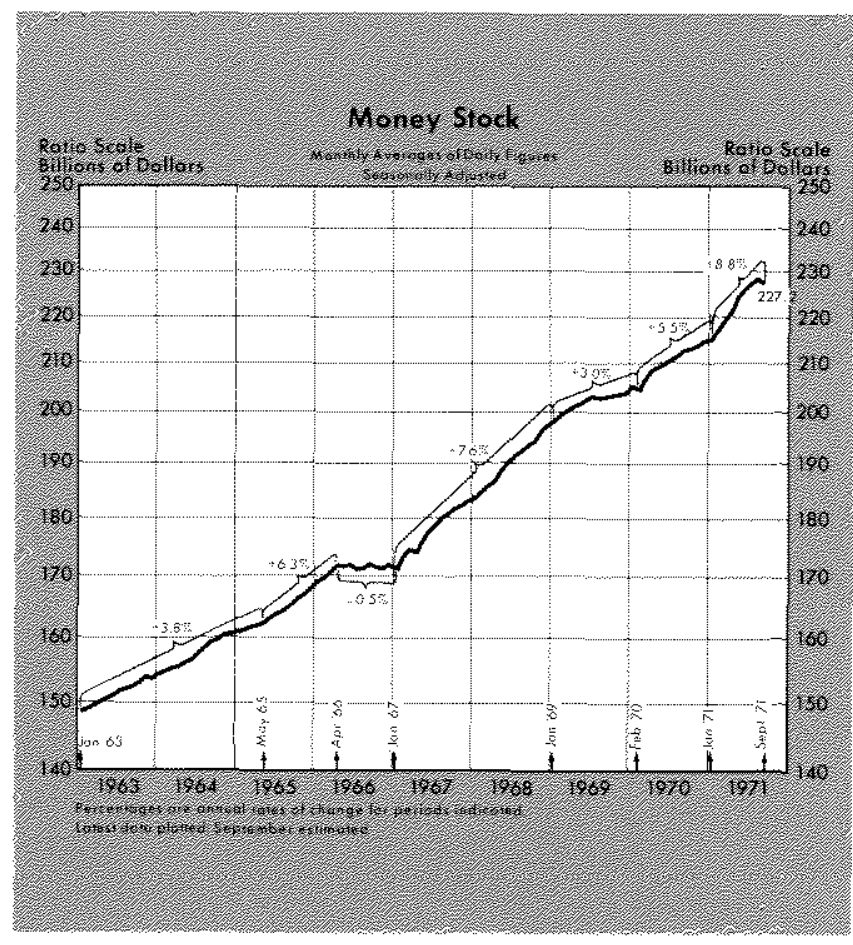

about equal to the growth of the economy's productive potential, or about 4 per cent per year under present circumstances. Whether a policy of moderate monetary growth supplemented with Government intervention in private wage and price policy can restore high employment with price stability more quickly than without $\mathrm{such}$ a supplement is problematical.

Recent monetary developments, if continued, would provide the underlying basis for the control of inflation. After increasing at a 12.5 per cent annual rate from January to June, the money stock has slowed to about a 3 per cent annual rate of increase from June to September. If monetary actions are to contribute towards the battle against inflation, moderate monetary expansion must be continued until a trend rate of money growth is established more in line with the growth of productive potential. 